\title{
Flame Spread over Binary Mixed Liquid Fuels-Super-Flash/Super-Flash Mixed Condition
}

\author{
Koichiro Sasaki, Akihiko Ito, Hiroyuki Torikai \\ Department of Intelligent Machines and System Engineering, Hirosaki University, Hirosaki, Japan \\ Email: h14ms611@hirosaki-u.ac.jp
}

Received 16 November 2015; accepted 14 December 2015; published 17 December 2015

Copyright (C) 2015 by authors and Scientific Research Publishing Inc.

This work is licensed under the Creative Commons Attribution International License (CC BY).

http://creativecommons.org/licenses/by/4.0/

(c) (i) Open Access

\begin{abstract}
In this study, we investigate the flame spread characteristics of binary mixed liquid fuels that are both in super-flash condition. We propose a method for estimating flashpoint and flame spread rate for binary mixed liquid fuels from binary vapor concentration distribution and compare these estimated values with experimental results. In addition, we measure the flame height and center of the flame leading edge for binary mixed liquid fuels. The results show that, when the flashpoint of each single fuel is known, the flashpoint of the binary mixed liquid fuel can be calculated. Moreover, the fuel that most influence combustion changes near the intersection of vapor concentration distribution in accordance with Raoult's law. Photographs of the flame indicate discontinuity. We can calculate flame spread rate by using the ratio of each diffusion coefficient to judge equivalently. Finally, it is found that the flame height and center of flame leading edge are proportional to total vapor concentration of the binary mixed liquid fuels.
\end{abstract}

\section{Keywords}

Flame Spread, Binary Mixed Liquid Fuels, Raoult's Law, Flashpoint, Super-Flash Condition

\section{Introduction}

Recently, serious disasters related to flame spread over liquid fuel such as tsunami fires happened during the Great East Japan earthquake in 2011. With this background, the study of flames spread over liquid fuel has drawn current interest, because of its relevance to fire safety and our basic curiosity about its complex mechanism. A series of studies are performed to understand the mechanism on alcohols [1]-[13]. But there are few studies of flame spread over binary mixed liquid fuels. This flame spread phenomenon is more similar to the real situation. So this study is needed to prevent unexpected damage. 
The flame spread characteristics of mixed liquid fuel depend on the distribution of vapor concentration by each liquid component that is formed. However, the relationship between vapor concentration distribution and flame spread rate is not clear. The purpose of this study is to reveal the relationship between vapor concentration distribution of mixed liquid fuel and flame spread rate. In this study, we try ethanol-methanol combinations which are both in super-flash condition. We measure distribution of vapor concentration and flame spread rate of binary mixed liquid fuels under these conditions and consider the relationship.

\section{Estimation of Flashpoint and Flame Spread Rate for Binary Mixed Liquid Fuels}

\subsection{Flashpoint of Binary Mixed Liquid Fuels}

To derive the flashpoint of binary mixed liquid fuels, we measured the vapor concentration of binary mixed liquid fuels in accordance with Raoult's law [14]. The flashpoint of binary mixed liquid fuels depends on the composition of each liquid composition. So it is very hard to measure the flashpoint for all liquid compositions. With this background, we examined prediction methods of the flashpoint of binary mixed liquid fuels using the flashpoint of simple ingredients and Raoult's law. In this study, we used vapor concentration at $1 \mathrm{~mm}$ from the liquid surface and regarded it as a quasi-steady condition. At first, we measured the flashpoint of each simple ingredient and defined $A$ which has lower flashpoint and $B$ which has higher flashpoint. And each flash point is determined as $T_{A} T_{B}$. Secondly, we calculated vapor concentration of each ingredient of the binary mixed liquid fuels. To keep the lower limit of the different flammable materials constant, we used a correction value. We multiplied the correction value $F$ by the vapor concentration of fuel $B C_{B}$ and summed up $F C_{B}$ and vapor concentration of fuel $A$. The sum is $c_{m}$. The equations are below:

$$
\begin{gathered}
F=c_{A} / c_{B} \\
c_{m}=c_{A}+F C_{B}
\end{gathered}
$$

At each liquid phase composition, if the vapor concentration is higher than the flammable material's lower limit $c_{m}$, the temperature at this time is defined as the flashpoint.

\subsection{Flame Spread Rate of Binary Mixed Liquid Fuels}

The flame spread rate of binary mixed liquid fuels depends on the fuel vapor concentration which is generated by each liquid composition. Therefore, we tried to calculate by converting total vapor concentration into single component fuel. Equation (2) indicates the concentration conversion equation

$$
C_{t}^{\prime}=X \cdot C_{t}
$$

$C_{t}^{\prime}$ is vapor concentration after conversion. $C_{t}$ is vapor concentration before conversion. The basic characteristics of mixed fuels under super-flash conditions are pre-mixed flame and burning velocity. To judge the vapor concentration of binary mixed liquid fuels by the burning velocity equivalently, we used the conversion value $X$ for single component fuel and composition of maximum burning velocity with an equivalent ratio of 1 . We calculated the maximum burning velocity of methanol as $55 \mathrm{~cm} / \mathrm{s}$ [15] and ethanol as $47 \mathrm{~cm} / \mathrm{s}$ [16].

Secondly, flame spread over mixed liquid fuels when both of them are in super-flash condition depends on total fuel vapor concentration. Therefore, we used Equation (3) to calculate flame spread rate over binary mixed liquid fuels

$$
V_{a}=c_{t} V_{i}
$$

$V_{a}$ is the flame spread rate of mixed fuels when both of them are in super-flash condition. $V_{i}$ is defined as flame spread rate per 1 vol\% by flame spread rate of the single component fuel divided by vapor concentration. If liquid temperature is determined, vapor concentration is also determined and if vapor concentration distribution is determined, flame spread rate is also determined. $c_{t}$ is the total vapor concentration of mixed fuels in each liquid fuel composition.

\section{Experimental Apparatus and Methods}

\subsection{Measurement of Flashpoint of Binary Mixed Liquid Fuels}

Figure 1 shows the experimental apparatus to measure flashpoint. We performed the flashpoint experiment 


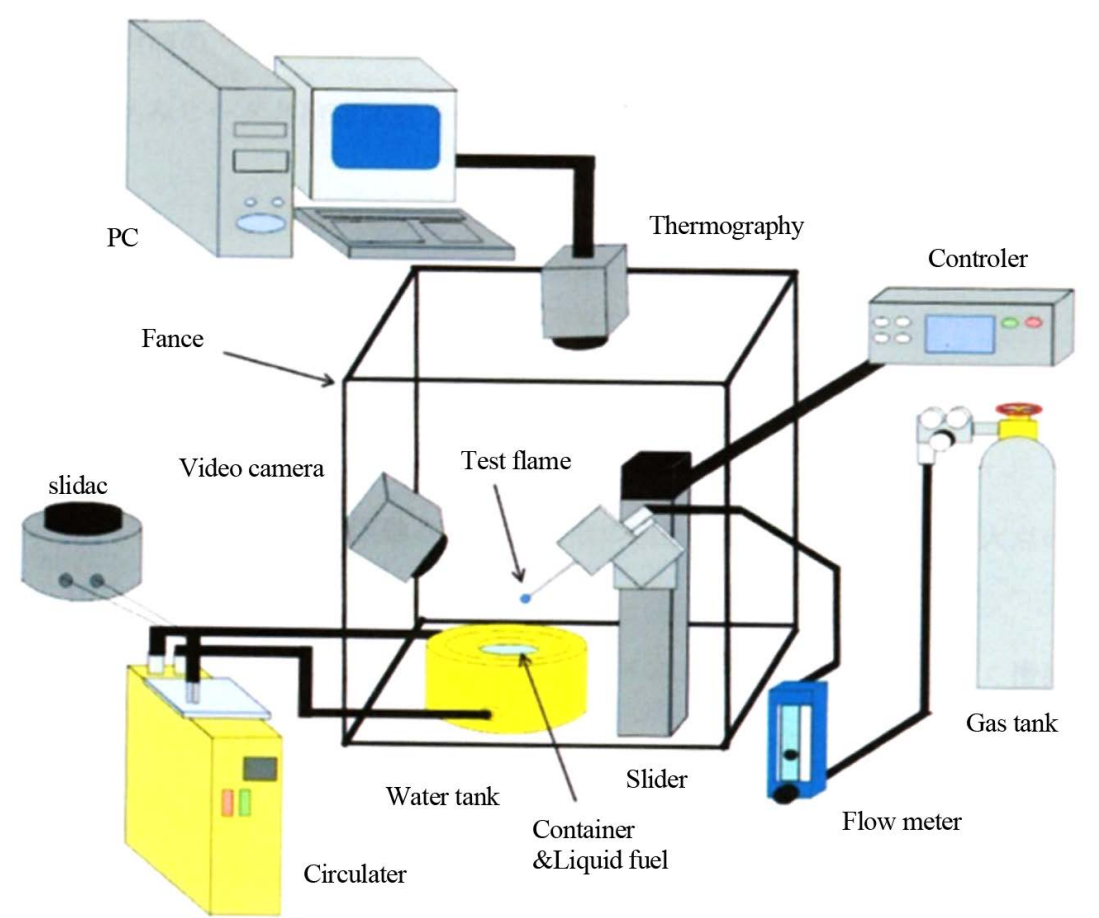

Figure 1. Experimental apparatus for measurement of flashpoint.

according to [JISK2256]. We poured the fuel $10 \mathrm{~mm}$ from edge of the fuel container to the fuel surface. When the test flame approached the fuel, the distance from the top of the test flame nozzle at the lowest to the fuel surface was $9.3 \mathrm{~mm}$. The fuel container was kept cool by cooling circulation water from a circulator to keep the fuel container temperature less than $10^{\circ} \mathrm{C}$ from the predicted flashpoint. When the fuel container temperature neared the flashpoint, we opened the cover and move the apparatus up and down. After that, we judged ignition by observation. We raised the liquid temperature $1^{\circ} \mathrm{C} / 1 \mathrm{~min}$ and measured for $30 \mathrm{~s}$. Finally, we performed the experiment five times for each condition and we used methanol and ethanol. The flashpoint of methanol is 15.6 $6^{\circ} \mathrm{C}$ and ethanol is $18^{\circ} \mathrm{C}$ in an open cup [17].

\subsection{Measurement of Flame Spread Rate over Binary Mixed Liquid Fuels}

Figure 2 shows the experimental apparatus to measure flame spread rate over binary mixed liquid fuels. The fuel container is made of aluminum and the size is $20 \mathrm{~mm}$ wide $250 \mathrm{~mm}$ long and $3 \mathrm{~mm}$ thickness. We performed the experiment in a wind tunnel with a counter current of $0.1 \mathrm{~m} / \mathrm{s}$. The cross-sectional size was $70 \mathrm{~mm} \times$ $70 \mathrm{~mm}$ and the length was $300 \mathrm{~mm}$. To keep the initial fuel temperature constant, we set aluminum piping under the fuel container with diameter $10 \mathrm{~mm} \times$ length $270 \mathrm{~mm}$ and circulated water. We used nichrome wire to ignite and filmed by video camera (CASIO EX-F1). To measure liquid temperature, we used a thermocouple which was attached on the edge of the fuel container. We performed the experiment five times and the initial liquid temperatures were $18^{\circ} \mathrm{C}, 20^{\circ} \mathrm{C}, 24^{\circ} \mathrm{C}$ and $28^{\circ} \mathrm{C}$. The fuels were ethanol and methanol the same as the flashpoint measurement-both of them were in super-flash condition.

\subsection{Measurement of Flame Shape on Binary Mixed Liquid Fuels}

The spreading flame shape depends on vapor concentration distribution near the liquid surface. In this study, judging from the flame shape, it was a so-called "triple flame" structure. In this structure, the vapor concentration is rich near the surface and the flame shape changes toward the direction of height-vapor concentration is lean and vapor concentration seems to be a theoretical mixture ratio at the apex of flame curvature. We defined the maximum height from the liquid surface to the apex of flame curvature as flame center because the theoretical mixture of each liquid phase composition was not known. This is the inherent value for each liquid fuel. Thus we performed this experiment because we seemed to reveal the predominating liquid fuel of each liquid 


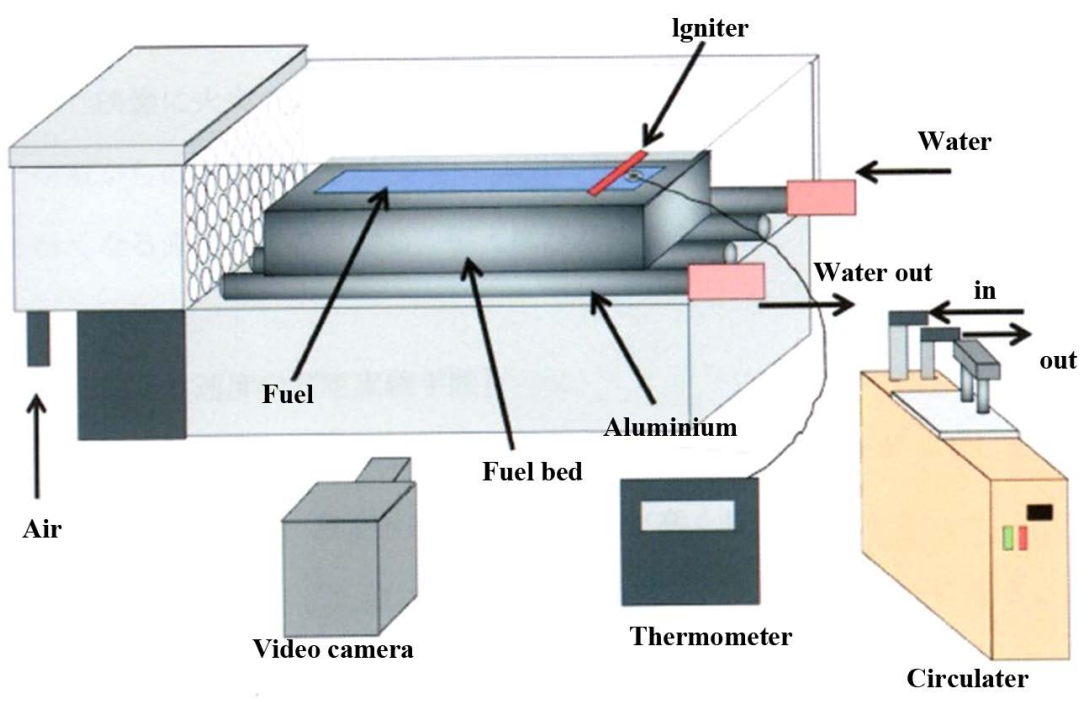

Figure 2. Experimental apparatus for measurement of flame spread rate.

phase composition by investigating the theoretical mixture ratio. Figure 3 shows the measurement method of flame center. We measured the maximum height of flame curvature from the liquid surface on the photographs which we filmed to measure flame spread rate. We indicated the relationship between measured flame height and vapor concentration distribution. Vapor concentration distribution is calculated by Equation (4) [14] and (5)

$$
\begin{gathered}
c_{i}^{*} / c_{s}=1-\operatorname{erferf}(y / \sqrt{4 D t}) \\
c_{i}^{*}=\alpha k c_{s}
\end{gathered}
$$

where $k$ is the infrared absorption coefficient [14]. $c_{s}$ is saturated vapor concentration calculated by the literature [18] [19]. $D$ is the diffusion coefficient which depends on temperature and pressure. $D$ can be calculated by equation (6) [20] and using the temperature in the laboratory $T_{0}$ and pressure $P$

$$
D=D_{0}\left(T_{0} / 273\right)^{2}\left(P_{0} / P\right)
$$

where $D_{0}$ is the diffusion coefficient at $0^{\circ} \mathrm{C} 1 \mathrm{~atm}$ (standard conditions) and methanol is $0.135 \mathrm{~cm}^{2} / \mathrm{s}$, ethanol is $0.1020 \mathrm{~cm}^{2} / \mathrm{s}[21] . P_{0}$ is atmospheric pressure.

\subsection{Measurement of Flame Height on Binary Mixed Liquid Fuels}

We measured flame height and flame center at the same time. Figure 4 shows the measurement method for flame height. We investigated how the flame shape changes at each liquid phase composition. In the photographs, we defined the maximum height of blue flame by eyesight from the liquid surface as flame height. We indicated the relationship between flame height and vapor concentration distribution calculated by Equation (5) and Equation (6).

\section{Experimental Results and Examination}

\subsection{Appearance of Flame Spread on Binary Mixed Liquid Fuels}

Figure 5 shows the appearance of flame spread on methanol/ethanol mixed fuels at $20^{\circ} \mathrm{C}$. The appearances are different due to the component of binary mixed liquid fuels. Based on these photographs, we considered the relationship between vapor concentration distribution and flashpoint and flame spread rate.

\subsection{The Relationship between Flashpoint and Liquid Fuel Composition}

Figure 6 shows the calculation result of flashpoint of methanol/ethanol mixed liquid fuels. The more the compo- 


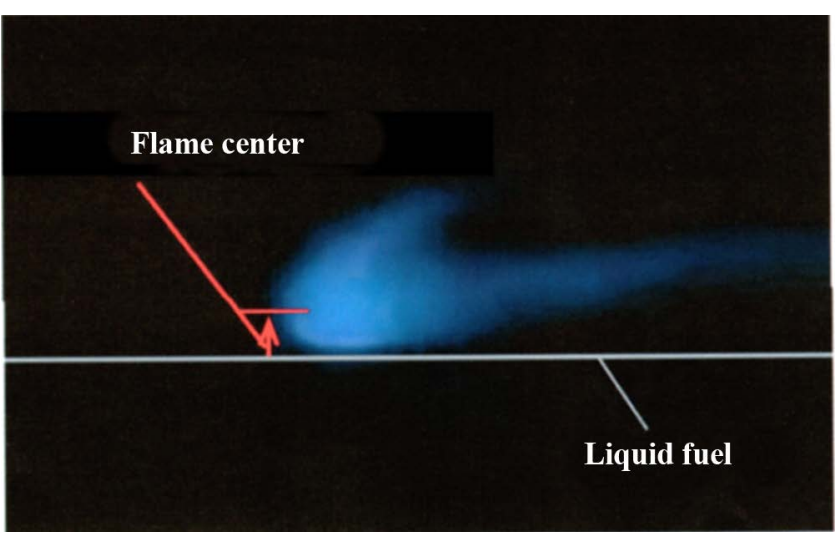

Figure 3. Measurement of flame center.

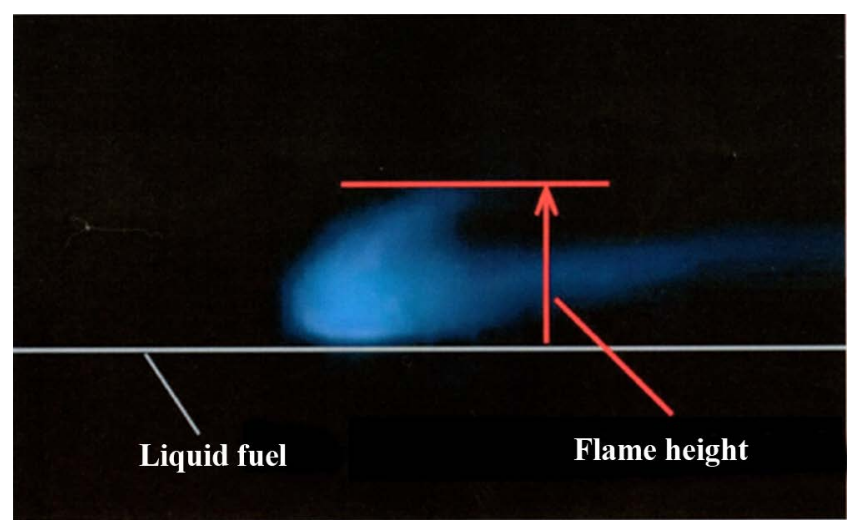

Figure 4. Measurement of flame height.

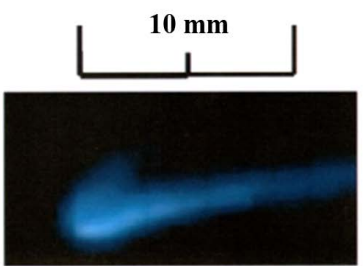

Ethanol $100 \%$

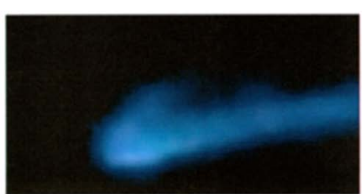

Methanol 20\%・ Ethanol 80\%

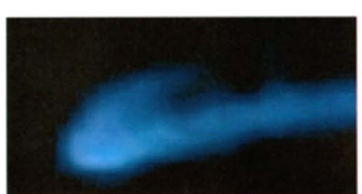

Methanol 30\% • Ethanol 70\%

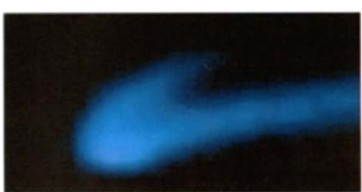

Methanol 100\%

Figure 5. Photographs of flame $\left(T=20^{\circ} \mathrm{C}\right)$.

sition of ethanol increases, the less the flashpoint decreases. This is because the vapor of methanol increases near the liquid surface and it reaches the lower limit concentration. Figure 7 shows a comparison of experimental results and estimated results using Equation (1) and Equation (2).

This is the better method to predict flashpoint because the estimated result and experimental result match well.

Considering that methanol vapor tends to increase, in case a gap is generated, it needs to be a lower value than real one. But considering that the flashpoint is measured under higher temperature than the estimated one, it is thought that when methanol vapor concentration increases, ethanol vapor concentration has an influence on the 


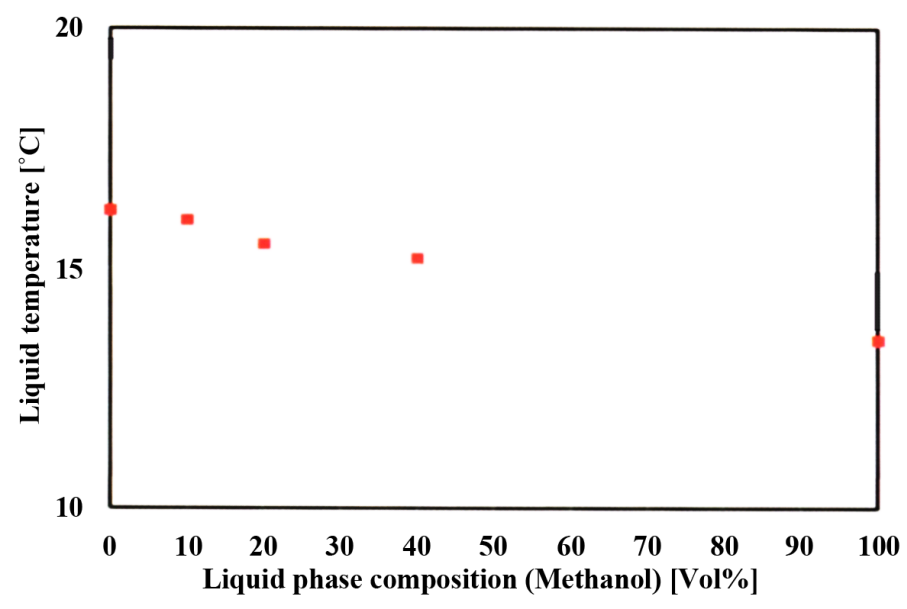

Figure 6. Flashpoint of binary liquid fuels.

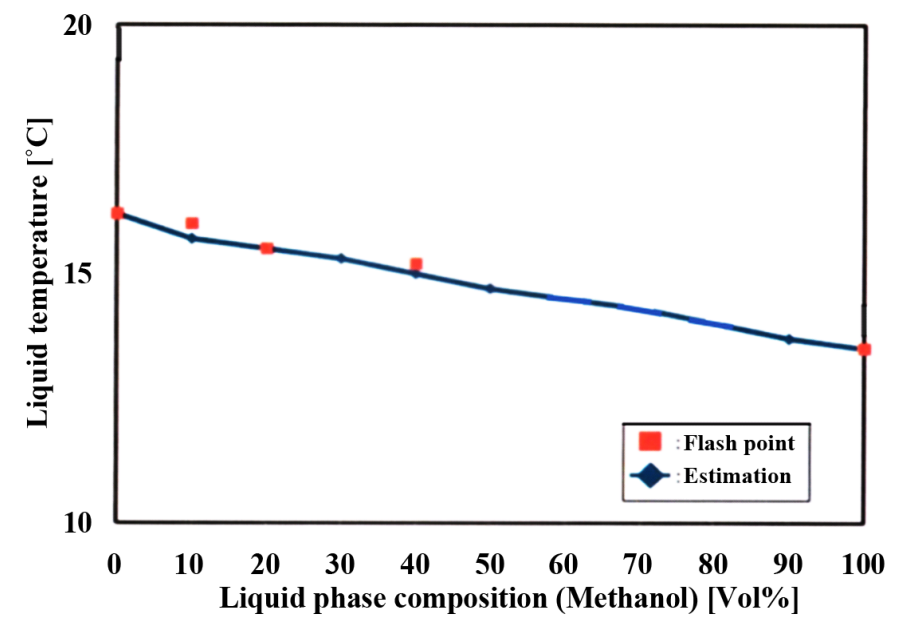

Figure 7. Comparison of experimental result and estimated value of flashpoint.

flashpoint. The reason why we couldn't measure flashpoint under 60 - 90 methanol composition, is because the gap between flashpoint and burning point is small in the case where methanol liquid composition increases.

\subsection{Relationship between Flame Spread Rate and Distribution of Vapor Concentration}

Figure 8 shows the relationship between liquid composition and flame spread rate under each liquid component. Flame spread rate under super-flash condition tends to increase at the same time the methanol composition increases. But when the liquid temperature is $28^{\circ} \mathrm{C}$, flame spread rate is almost constant. This is because methanol and ethanol reach stoichiometric ratio. In addition, the flame spread rate is discontinuous at $20^{\circ} \mathrm{C}$ with $20 \%-30 \%$ methanol composition and $24^{\circ} \mathrm{C}$ with $30 \%-40 \%$ methanol composition as shown in Figure 8 . It is thought that the dominant liquid fuel changes. Figure 9 shows the relationship between vapor concentration and methanol liquid phase. In Figure 8, the dominant liquid fuel is changed by around 20\%. From Equation (2), we changed ethanol to methanol vapor and methanol to ethanol vapor. The chain line in Figure 9 shows the converse value which is mainly fuel vapor concentration. Figure 10 shows the comparison with calculated flame spread rate using Equation (3) with equivalent concentration and experimental results. Estimated values of flame spread rate correlate with experimental results well. Figure 5 shows fuel temperature of $20^{\circ} \mathrm{C}$. We focused on the circle in Figure 8. To examine the cause of discontinuity, we compared the flame around the discontinuity point. Compared with the images of $20 \%$ methanol composition and $30 \%$ methanol composition, the flame shape of $20 \%$ methanol composition is similar to the flame of ethanol $100 \%$ ratio. On the other hand, the flame of methanol 


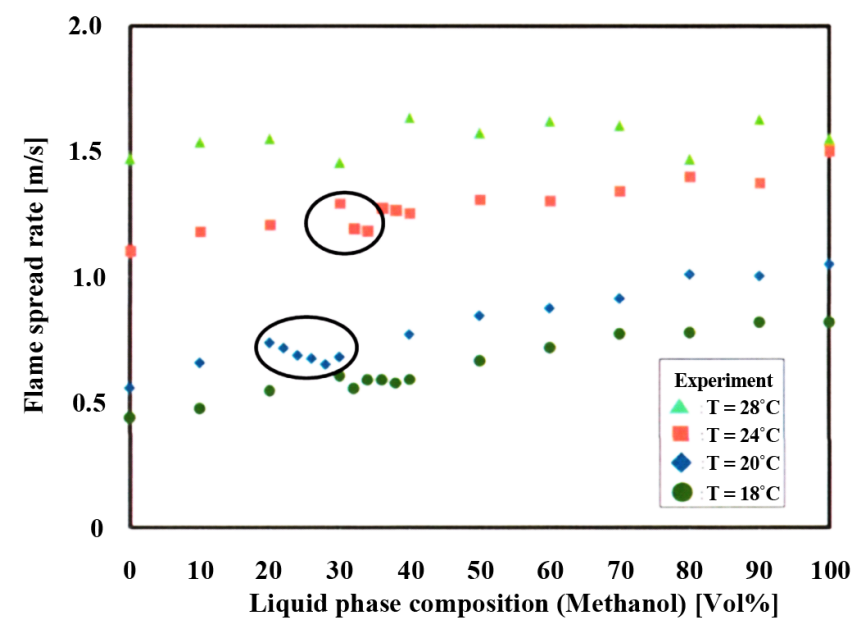

Figure 8. Flame spread rate on binary mixed liquid fuels.

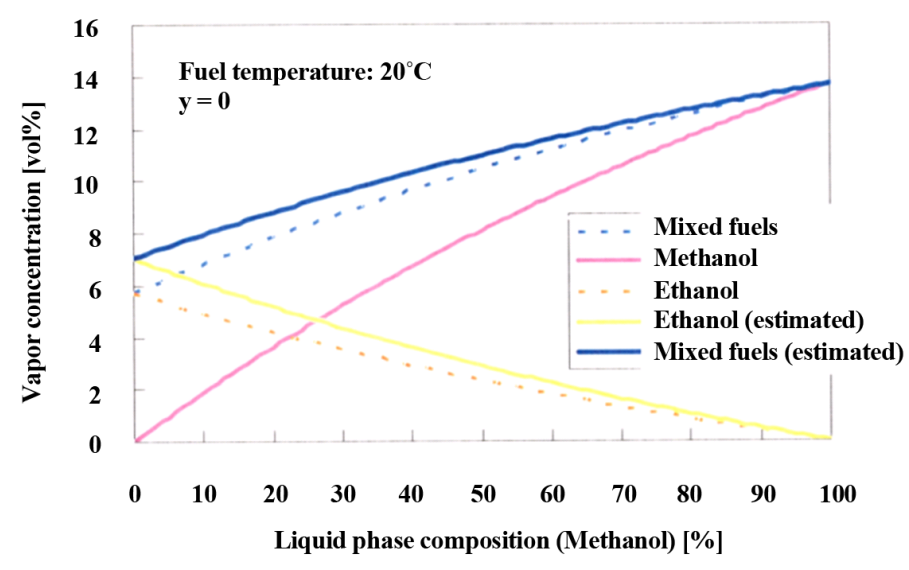

Figure 9. Vapor concentration of binary mixed liquid fuels.

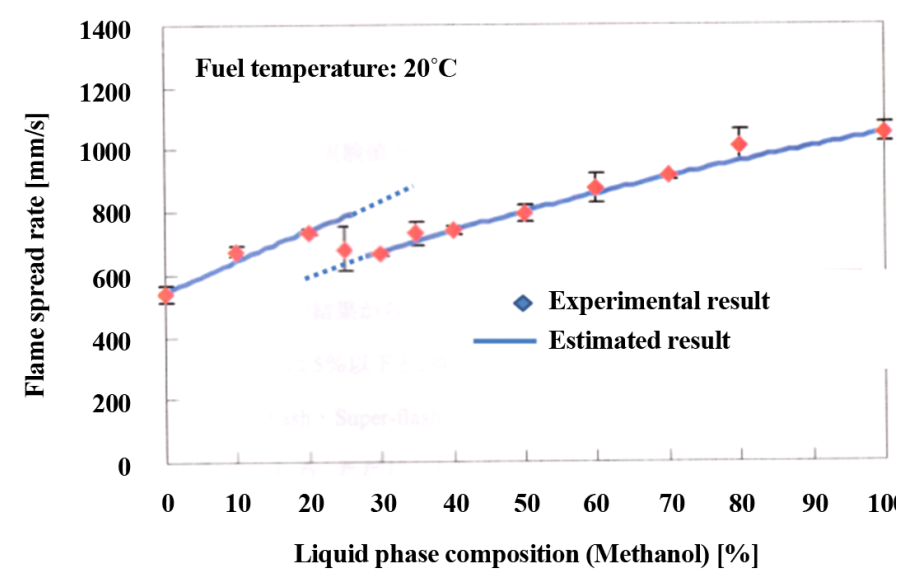

Figure 10. Estimation of flame spread rate on binary mixed liquid fuels.

$30 \%$ is similar to the flame of methanol $100 \%$. Therefore, the cause of decline in flame spread rate is substituted of mainly fuel vapor. In short, binary mixed liquid fuels which are both in super-flash condition have boundary values for which the dominant fuel changes. By the way, Figure 11 shows a comparison of experimental results and estimated values of flame spread rate. When liquid temperature is low, a discontinuity point appears. But at $28^{\circ} \mathrm{C}$, the discontinuity point doesn't appear and the flame spread rate is almost constant. The reason seems to be 


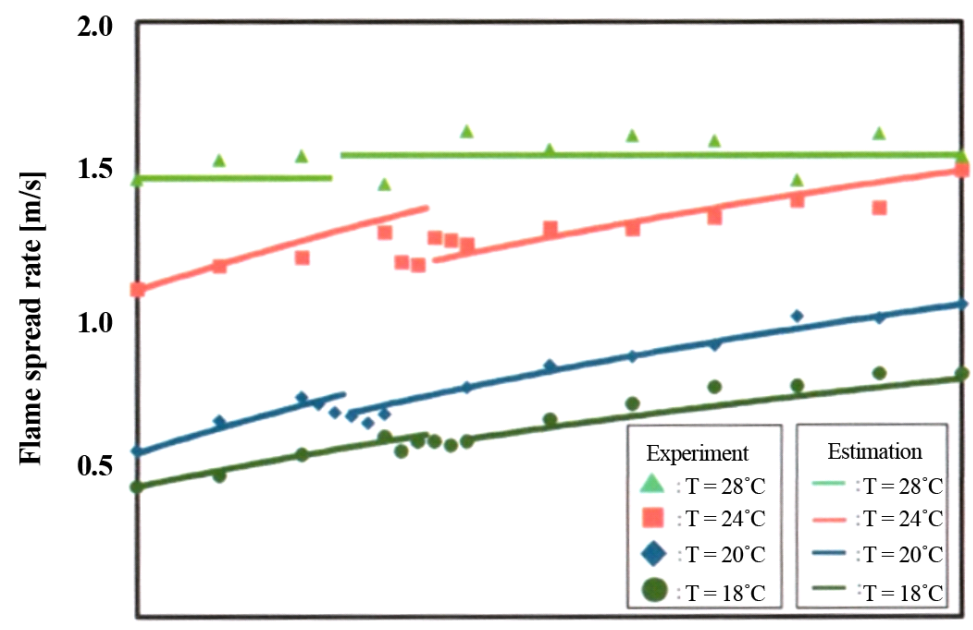

Liquid phase composition (Methanol) [Vol\%]

Figure 11. Comparison of experimental results and estimated values.

that flammable vapor on the liquid surface reaches the theoretical mixture ratio. But by the influence of the rise of liquid fuel, a gap is generated between experimental value and estimated value. So we need to consider equivalent concentration. As for flame spread over binary mixed liquid fuel, the predominating liquid fuel changes at the cross section of vapor concentration distribution in accordance with Raoult's law. To calculate flame spread rate over binary mixed liquid fuels by vapor concentration, one liquid fuel must be converted to the other' by Equation (2). The calculation equation is indicated below:

$$
\begin{gathered}
c_{t}=c_{b}+c_{a} X \\
V_{i}=V_{b} / c_{b}
\end{gathered}
$$

where $V_{a}$ is flame spread rate over binary mixed liquid fuels, $V_{i}$ is flame spread rate per 1 vol\% of predominated liquid fuel and $c_{t}$ is total vapor concentration at each liquid phase composition. We defined the extinguish distance as $1 \mathrm{~mm}$ from the liquid surface. Raoult's law is adopted on the liquid surface, but actually a fuel vapor distribution exists. So we considered this. Vapor concentration distribution depends on the kinds of liquid fuel. So we used a conversion coefficient $X$ which is the ratio of diffusion coefficient. Thus to calculate flame spread rate over binary liquid fuels, we use Equation (9). If the value at extinguish distance $1 \mathrm{~mm}$ reaches the theoretical mixture ratio of each fuel, the flame spread rate is constant. From the experiment of measurement of vapor concentration and flame shape, if the liquid phase composition of methanol is $0 \%-25 \%$, we regarded the predominating liquid fuel to be ethanol. If the liquid phase composition of methanol is $26 \%-100 \%$, we regarded the predominating liquid fuel to be methanol. From Figure 9 and Figure 10, the experimental results and estimated results match well. In the case that liquid temperature is $28^{\circ} \mathrm{C}$, the flame spread rate is constant because ethanol and methanol reach the theoretical mixture ratio. We changed the predominating liquid fuel to $20 \%$ because the cross section of Raoult's law is near $20 \%$. However we found the result that the cross section didn't change, but the discontinuity point was displaced.

\subsection{Flame Center and Vapor Concentration on Binary Mixed Liquid Fuels}

Figure 12 shows the relationship between the flame center of vapor concentration distribution and each liquid phase composition at each liquid temperature. Vapor concentration is calculated by the vapor concentration distribution of the diffusion equation. Flame center and vapor concentration distribution rise proportionally with the increase of methanol composition. From this result, the lean limit of binary mixed liquid fuels seems to expand by increasing ethanol composition. But some calculation results which the flame center makes corresponding to vapor concentration distribution sometimes indicate more than the theoretical mixture ratio. So we need to consider a more accurate calculation method. 


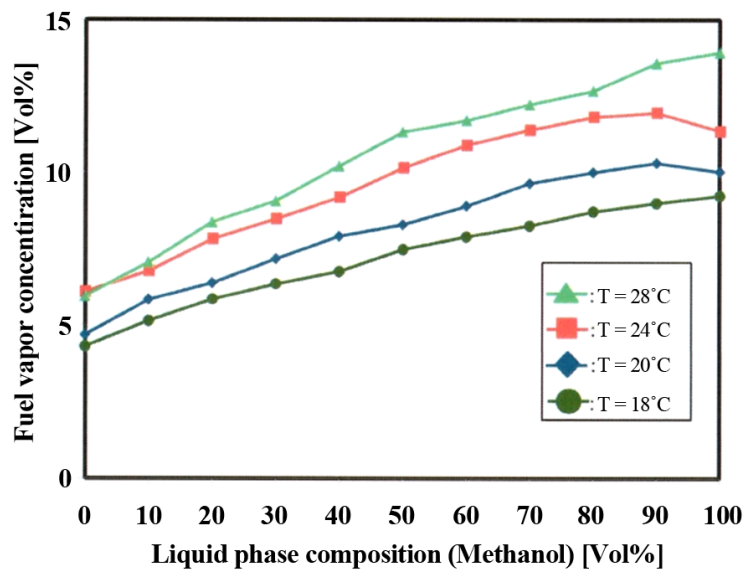

Figure 12. Flame center on binary mixed liquid fuels.

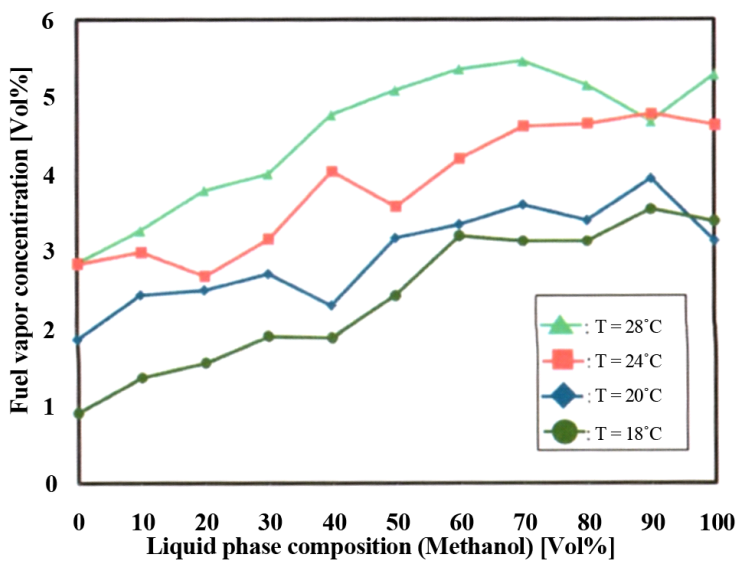

Figure 13. Flame height on binary mixed liquid fuels.

\subsection{Flame Height and Vapor Concentration on Binary Mixed Liquid Fuels}

To calculate the flashpoint of binary mixed liquid fuels, if the flashpoint of a single liquid fuel is known, we can calculate one liquid fuel's flammable lower limit by re-compensating the other using Raoult's law and a correction value. Figure 13 shows the relationship between flame height of vapor concentration distribution and each liquid phase composition at each liquid temperature. Flame height and vapor concentration rise proportionally to the rise of methanol composition in the same way as the flame center. Thus the lean limit of binary mixed liquid fuels also expands by increasing ethanol composition. But the judgement of flame height is by eyesight and the blue flame height changes at each place. So we need to consider more precise method.

\section{Conclusions}

We aim to establish a prediction method by using the mixed liquid fuels methanol and ethanol in super-flash condition and Raoult's law to calculate vapor concentration distribution. The conclusions are follows:

1) To calculate the flashpoint of binary mixed liquid fuels, if the flashpoint of a single liquid fuel is known, we can calculate one liquid fuel's flammable lower limit by re-compensating the other using Raoult's law and a correction value.

2) For the flame spread rate over binary mixed liquid fuels, the predominating liquid fuel changes near the cross section of vapor concentration distribution in accordance with Raoult's law.

3) For the discontinuity of flame spread rate over binary mixed liquid fuels, we confirm the decrease of flame spread rate by experiment. In addition, flame shape changes near the discontinuity point. From these results, we find discontinuity as a phenomenon. 
4) When the liquid temperature is $28^{\circ} \mathrm{C}$, the flame spread rate is constant. This is why flammable vapor formed near the liquid surface reaches theoretical mixture ratio.

5) In the case that we calculate flame spread rate over binary mixed liquid fuel by vapor concentration distribution from flame spread rate over single liquid fuel and Raoult's law, we cannot calculate it by the total amount of binary mixed liquid fuel vapor. So we can calculate the flame spread rate by using a conversion coefficient to judge the liquid fuels equivalently.

6) The flame center of binary mixed liquid fuels is proportional to the rise of total vapor concentration of binary mixed liquid fuels.

7) The flame height on binary mixed liquid fuels is proportional to the rise of total vapor concentration of binary mixed liquid fuels.

\section{Acknowledgements}

We would like to thank Kenji Takimoto working in Shigeru Corporation, Ltd and Kota Mikami working in Toshiba Plant Systems and Services Corporation for experimental supports and discussions.

\section{References}

[1] Burgoyne, J.H., Roberts, A.F. and Quinton, P.G. (1968) The Spread of Flame Across a Liquid Surface. I. The Induction Period. Proceedings of the Royal Society, A308, 39-53. http://dx.doi.org/10.1098/rspa.1968.0206

[2] Burgoyne, J.H., Roberts, A.F. and Quinton, P.G. (1968) The Spread of Flame Across a Liquid Surface. II. Steady-State Conditions. Proceedings of the Royal Society, A308, 55-68. http://dx.doi.org/10.1098/rspa.1968.0207

[3] Burgoyne, J.H., Roberts, A.F. and Quinton, P.G. (1968) The Spread of Flame Across a Liquid Surface. III. A Theoretical Model. Proceedings of the Royal Society, A308, 69-79. http://dx.doi.org/10.1098/rspa.1968.0208

[4] Glassman, I., Hansel, J. and Eklund, T. (1969) Hydrodynamic Effects in the Flame Spreading, Ignitability and Steady Burning of Liquid Fuels. Combustion and Flame, 13, 99-101. http://dx.doi.org/10.1016/0010-2180(69)90037-6

[5] Kikaino-Kenkyu, I.H. (1971) Hyomenwokanetsusaretaekitai no ryudo. Kikai no Kenkyu, 23, 1505-1510.

[6] Akita, K. and, Fujiwara, O. (1971) Pulsating Flame Spread along the Surface of Liquid Fuels. Combustion and Flame, 17, 268-269. http://dx.doi.org/10.1016/S0010-2180(71)80172-4

[7] Akita, K. (1972) Some Problems of Flame Spread along a Liquid Surface. Symposium (International) on Combustion, 14, 1075-1083. http://dx.doi.org/10.1016/S0082-0784(73)80097-9

[8] Newman, J.S. (1979) Lase Droplet Velocimeter Measurements of the Gas and Liquid Flow Fields Induced by Flame Propagation over a Liquid Surface. MSE Thesis, Princeton University, Princeton.

[9] Hirano, T., Suzuki, T., Mashiko, I. and Tanabe, N. (1980) Gas Movements in Front of Flames Propagating across Methanol. Combustion Science and Technology, 22, 83-91. http://dx.doi.org/10.1080/00102208008952373

[10] Mackinven, R., Hansel, F. and Glassman, I. (1970) Influence of Laboratory Parameters on Flame Spread across Liquid Fuels. Combustion Science and Technology, 1, 293-306. http://dx.doi.org/10.1080/00102206908952209

[11] Matsumoto, Y. and Saito, T. (1980) Ekimennenshodenpanikansurukenkyu. JSEM, 46, 996-1006. (in Japanese)

[12] Matsumoto, Y. and Saito, T. (1981) Flame Propagation over Liquid Fuel at Sub-Flash Temperature. Bulletin of JSEM, 24, 123-138.

[13] Takahashi, K., Ito, A., Kudo, Y., Konishi, T. and Saito, K. (2008) Scaling Analysis on Pulsating Flame Spread over Liquids. International Journal of Chemical Engineering, 2008, Article ID: 178292. http://dx.doi.org/10.1155/2008/178292

[14] Takimoto, K., et al. (2008) Speech Papers Correction, Combustion Symposium Part 46, 286-287.

[15] Hirano, T. (1986) Nenshogaku-Nenshogensho to sonoseigyo-, Kaibun-do, 49-63. (In Japanese)

[16] Gulber, O.L. (1982) Laminar Burning Velocities of Methanol, Ethanol and Isooctane-Air Mixtures. Proceedings of the Combustion Institute, 19, 275-281.

[17] Drysdale, D. (1999) An Introduction to Fire Dynamics. 2nd Edition, Wiley, Hoboken, 203.

[18] Ueda, M. (Year) Shitsudo to Johatsu—Kiso to Keisokugijutsu Made. Colona Co., 2-4. (In Japanese)

[19] Kuratera, T., Terasaki, K., Nagai, N. and Ito, K. (1982) Kogyo netsurikigaku. Asakurashoten, Tokyo, 96-98. (In Japanese)

[20] Katayama, K., et al. (1986) JSME Data Book: Heat Transfer. 4th Edition, JSME, Tokyo, 114-115.

[21] Kato, Y. (1964) Heat Dennetsu Gairon. Yokendo, Tokyo, 222-223. (In Japanese) 


\section{Nomenclature}

$C_{a}$ : Under limiting concentration of single component of liquid fuel [vol\%]

$C_{b}$ : Under limiting concentration of single component of liquid fuel [vol\%]

$C_{A}$ : Vapor concentration of fuel A [vol\%]

$C_{B}$ : Vapor concentration of fuel B [vol\%]

$C_{m}$ : Under limiting concentration of binary mixed liquid fuels [vol\%]

$F$ : Correction value [-]

$C_{t}$ : Total vapor concentration at each liquid phase composition [vol\%]

$X$ : Vapor conversion coefficient [-]

$C_{t}^{\prime}$ : Vapor concentration after conversion [vol\%]

$V_{a}$ : Flame spread rate over binary mixed liquid fuels $[\mathrm{m} / \mathrm{s}]$

$V_{i}$ : Flame spread rate over mainly liquid fuel per $1 \mathrm{vol} \%[\mathrm{~m} / \mathrm{s}]$

$C i$ : Vapor concentration of ingredient $i$ of binary mixed liquid fuels [vol\%]

$C_{i}^{*}$ : Vapor concentration of ingredient ionly [vol\%]

$C_{s}$ : Saturated vapor concentration [vol\%]

$y$ : The height from liquid surface $[\mathrm{mm}]$

$T$ : Temperature $\left[{ }^{\circ} \mathrm{C}\right]$

$T_{0}$ : Temperature in laboratory $\left[{ }^{\circ} \mathrm{C}\right]$

$T_{A}$ : Flashpoint of fuel which has lower flashpoint $\left[{ }^{\circ} \mathrm{C}\right]$

$T_{B}$ : Flashpoint of fuel which has higher flashpoint $\left[{ }^{\circ} \mathrm{C}\right]$

$t$ : Time [s]

$P$ : Pressure $[\mathrm{Pa}]$

$D$ : Diffusion coefficient $\left[\mathrm{cm}^{2} / \mathrm{s}\right]$

$D_{0}$ : Diffusion coefficient at $0{ }^{\circ} \mathrm{C}, 1 \mathrm{~atm}\left[\mathrm{~cm}^{2} / \mathrm{s}\right]$

$\alpha$ : Inherent value of each liquid fuel [-]

$k$ : Radiation absorption coefficient [/m] 